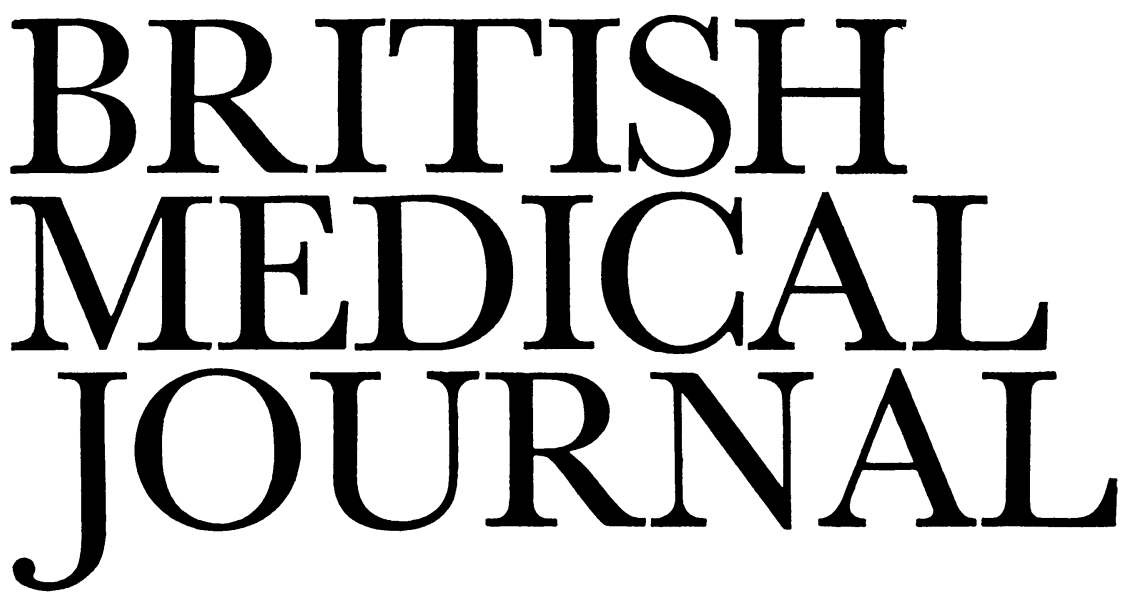

LONDON, SATURDAY 21 MARCH 1981

\title{
Withholding treatment in infancy
}

The spotlight of current journalistic attention has moved from Britain's neurologists and their definition of brain death to paediatricians and their treatment of infants with severe physical and mental handicaps. Several doctors have declared publicly that they recommend that treatment should be withheld from infants with severe and only partly correctable disabilities; their critics have argued that withholding treatment-and in some cases sedating, withholding food, and giving only water-amounts to killing the child and as such is a criminal offence.

In common with many other medical controversies this one has its origins in technical advances. In particular, intensive care units and surgery in the first few days after birth can preserve the lives of many infants who would soon have died from congenital defects such as myelomeningocele, intestinal atresias, and severe heart lesions. Sadly, long-term follow-up of the survivors of specialist neonatal care has shown a wide range of results. Some children grow up physically and mentally normal; some are handicapped but have adjusted well to their residual disabilities; but a few have remained substantially handicapped, mentally and physically, despite repeated operation. In such cases parents may spend the rest of their lives caring for their disabled child, and often the emotional and physical strain precipitates the break-up of the marriage and causes psychological problems in healthy siblings. Of 323 infants with myelomeningocele seen and treated on the first day of life between 1959 and 1963, long-term follow-up ${ }^{1}$ showed that one-third of the 134 survivors had severe physical handicaps combined with moderate to severe mental handicap. Their families had to cope with the combination of flaccid paraplegia, recurrent urinary infections, incontinence, and sometimes blindness and fits, in children with intelligence quotients of 80 or below. The cumulative experience of the misery that can result from medical intervention that prolongs life without correcting disabilities has led most paediatricians to adopt a policy of selective treatment. ${ }^{1-3}$

Such a policy recognises that medical ethics must change to take account of technical advances-and that once convinced of its practical and moral justification society will support such a change. The macabre farce of the prolonged deaths of President Tito and General Franco helped convince the public that medical treatment could and should be stopped long before the last heart beat of a dying man. The same principle is now widely accepted in the case of young patients with fatal diseases: treatment that can only prolong suffering is futile and should be replaced by an acceptance of the inevitability of death. Within the space of a single generation termination of pregnancy has become accepted as routine when the fetus is at high risk of mental or physical defect (though opinion is much more divided on the "social" indications for abortion). Critics of the Abortion Act 1967 warned that it might pave the way for euthanasia of handicapped infants. They were right - to some extent-for severely handicapped infants are now seen by many doctors and parents as having less than an absolute claim to every possible form of medical treatment. Surgical advances have given doctors the power to cobble together some sort of continuing existence for virtually every infant, no matter how extreme and multiple the congenital defects. To exercise that power without careful examination of the consequences would be irresponsible and, indeed, arguably unethical. Yet most doctors-and most people-are gradualists. They accept that withholding treatment may be a compassionate decision when the infant's handicaps are largely irremediable; they are less sanguine about hastening death by heavy sedation and withholding food. Some form of sedation is, however, surely warranted in the case of an infant with Down's syndrome and duodenal atresia for whom no operative treatment is intended. Problems of this kind cannot be ducked by doctors and nurses; they have to choose between treatment and non-treatment, sedation or not, and on the basis of a set of rational, consistent criteria rather than individual ad-hoc judgments.

What, then, should the medical response be to the recent wave of criticisms of selective treatment policies and their practical application? As Mr Ian Kennedy showed in his 1980 $\mathrm{BBC}$ Reith lectures, non-medical commentators have given careful thought to these problems without being able to produce solutions any more appealing than the current practice of leaving the decisions to be made by doctors. Yet those same doctors can no longer rely on paternalistic assertion of good intentions. Their treatment of handicapped infants must be seen to be based on a clear distinction between facts, which should be established by reliable evidence, and opinions, which may be widely divergent. Firstly, then, any discussion of the management of infants with birth defects requires soundly based information on prognosis. What is the child's outlook without treatment; and what is the range of outcomes with medical and surgical intervention? When such information is available-as it is, for example, in the case of infants with meningomyelocele and spina bifida-objective clinical 
tests can be applied before operation to estimate the extent of residual disability later in childhood. When such evidence on prognosis is lacking a selective policy cannot be justified.

Armed with a reliable assessment of outcome, the paediatrician can then discuss the treatment options with the parents. ${ }^{4}$ -a step urged by the British Paediatric Association in its statement ( $p$ 1001) issued earlier this week. Medical and public opinions vary on this issue (just as they do on the related issue of termination of pregnancy). Clearly the paediatrician should not try to impose his views on the parents; he should explain the clinical findings, give his advice sympathetically and patiently, and await their reaction. Parents may want time to think or to discuss the choices available to them. If their views are in conflict with those of the paediatrician, he should either accept their decision or refer the infant for assessment to a colleague more in sympathy with their beliefs.

Decisions on whether or not to treat an infant need to be made openly if those concerned are not to carry unacceptable burdens of responsibility. The essential first step in the management of infants with severe defects is specialist assessment, accurate diagnosis, and the use of objective tests to provide a prognosis. Such an assessment will almost certainly need to be made in a district hospital: well-intentioned, quiet infanticide in a cottage hospital is an unacceptable, unethical anachronism.

Most infants referred for specialist assessment will be treated. A few will have such a combination of physical and mental defects that the most optimistic outlook is for continuing severe handicaps; in such cases treatment may be withheld and the infant may soon die. Such deaths should be included in the discussion at regular unit audit meetings to examine all deaths and medical and surgical complications. Any reasonable, compassionate treatment policy ought to be able to withstand open examination.

Public anxiety would surely be allayed by an open policy of this kind. It reflects current practices and ethical beliefs, though by no means all doctors or every public critic will agree with it. Whether or not withholding treatment could contravene the law is a matter that only the courts can decide; but lawyers have always claimed that the great virtue of the common-law system is its flexibility, which gives it scope to adapt to technical, moral, and ethical changes in our society.

1 Lorber J. Results of treatment of myelomeningocele. An analysis of 524 unselected cases, with special reference to possible selection for treatment. Dev Med Child Neurol 1971;13:279-303.

2 Lorber J. Spina bifida cystica. Results of treatment of 270 consecutive cases with criteria for selection for the future. Arch Dis Child 1972;47: 854-73.

${ }^{3}$ Keys Smith G, Durham Smith E. Selection for treatment in spina bifida cystica. Br Med F 1973; iv:189-97.

4 Ellis HL. Parental involvement in the decision to treat spina bifida cystica. Br Medf 1974 ;i:369-72.

\section{Epiphysitis in congenital dislocation of the hip}

Since its introduction, modern treatment of congenital dislocation of the hip has occasionally been marred by the occurrence of radiological changes in the upper femoral epiphysis similar to those seen in Perthes's disease. ${ }^{12}$ Success in reducing the dislocation and inducing normal development of the acetabulum has now become so predictable that these disturbances of growth are the most important cause of an unsatisfactory outcome.
Though no histological evidence is available, the changes are usually attributed to damage to the local blood supply. They range from spotty or irregular ossification of the femoral-head epiphysis to its much delayed appearance and failure to grow. ${ }^{3}$ Irregular ossification of the femur may prove only temporary and the hip may eventually be unblemished, but epiphysitis often goes on to lasting deformity of the upper end of the bone and osteoarthritis in early adult life. ${ }^{4}$ The appearance of any abnormality of ossification must, therefore, always cause anxiety, since the prognosis in the individual case is difficult. Changes in the metaphysial region seem especially likely to go on to serious distortion in the mature bone. ${ }^{6}$ On the whole, treatment has little to offer. In the early phases the damaged epiphysis is probably best managed by containment in the acetabulum, shallow though that may be. Though late distortion of the anatomy may be helped a little by surgery, the emphasis must be on prevention.

Epiphysitis is so unusual in untreated dislocations that it must be regarded as a complication of treatment. Not surprisingly, it has been seen more often in children presenting late, in whom reduction is more difficult, ${ }^{4}$ but another important especially susceptible group is the very young, under 3 months of age. ${ }^{6} 7$ Suspicion that the damage was caused by the trauma of manipulative reduction was confirmed in many centres where the complication became much less common on the adoption of gentler techniques of reduction by gradual traction over three or four weeks. ${ }^{3} 78$ Probably open reduction, too, has a better record than manipulation, though accurate assessment of its risks is difficult since surgical treatment is confined to patients with selected problems.

Epiphysitis cannot, however, be attributed only to the trauma of reduction. Many instances have been recorded in a dysplastic hip that has not needed reduction, ${ }^{9}$ and sometimes the opposite "normal" hip has also been affected. ${ }^{10}$ In such cases immobilisation alone must have been to blame. The evidence indicates that a position of flexion and full $90^{\circ}$ abduction, as in the "frog" plaster or Frejka pillow, is especially dangerous, ${ }^{311}$ and that the abducted, fully internally rotated posture is also unsafe..$^{12}$ Rigid splinting in more than $60^{\circ}$ abduction should certainly be avoided, and perhaps all extreme positions are dangerous.

Nowadays most infants with unstable hips have the diagnosis made at birth. In many cases, perhaps five out of six, the hip would stabilise spontaneously without treatment; but anxiety about possible problems later in the hip that does not stabilise has led to a policy of immobilising all unstable hips in abduction. This policy exposes infants to the risk of damage to the growth of the upper end of the femur, a sad enough complication of necessary treatment but a disaster when the need for splinting is in doubt. Splints should be used only with discretion. They remain indicated for hips that are dislocated or readily dislocatable at birth, for in these children the penalties of neglect can be severe. Even so, rigid splinting must be avoided. The popular malleable metal splints should be adjusted to allow a range of flexion and extension at the hip. Better still, perhaps, would be the greater use of devices (such as the Pavlik harness) that allow even more motion of the hip while still safely maintaining reduction. ${ }^{13}$

1 Evans EL. Late results of manipulative treatment of congenital dislocation of the hip. Br 7 Surg 1922;10:15-23.

${ }^{2}$ Fairbank HAT. Late results of treatment of congenital dislocations of the hip. Br $\mathcal{F}$ Surg 1922;10:24-37.

${ }^{3}$ Salter RB, Kostuik J, Dallas S. Avascular necrosis of the femoral head as a complication of treatment for congenital dislocation of the hip in young children: a clinical and experimental investigation. Can f Surg 1969; 12:44-60.

${ }^{4}$ Gage JR, Winter RB. Avascular necrosis of the capital femoral epiphysis as 